\section{Kossel, Albrecht}

H. Fiedler

Erfurt, Deutschland

Lebensdaten Albrecht Kossel (auch Ludwig Karl Martin Leonhard Albrecht Kossel) war deutscher Mediziner und Physiologe, geboren 1853 in Rostock, gestorben 1927 in Heidelberg. Im Medizinstudium in Straßburg wurde er besonders beeinflusst von $>$ Hoppe-Seyler, Felix. Nach seiner Promotion 1878 wurde er dessen Assistent. 1883 wurde er von E. Du Bois-Reymond zum Direktor der Chemischen Abteilung des Instituts für Physiologie in Berlin berufen. Ab 1895 war er Ordinarius des Lehrstuhls für Physiologie in Marburg und nach 1901 in Heidelberg. Nach seiner Emeritierung hat er bis zu seinem Tod das Institut für Proteinforschung in Heidelberg geleitet.

Verdienste In seiner wissenschaftlichen Arbeit konzentrierte sich Kossel auf die Chemie von Geweben und Zellen und besonders auf den Zellkern. Bereits 1869 hatte Friedrich Miescher das „Nuclein“ in Eiterzellen entdeckt. Kossel spaltete diese Substanz in Proteine und Nichtproteine. In den Histonen und Protaminen entdeckte und quantifizierte er die
Hexonbasen Arginin, Lysin und Histidin (sowie Agmatin in Fischsperma) und nutzte dazu das Kossel-Kutscher- oder Silber-Baryt-Verfahren (später durch die Flavianat-Methode ergänzt). Er untersuchte und charakterisierte die Arginase. In der Nukleinsäurefraktion isolierte er mit zahlreichen Mitarbeitern die 5 Purin- und Pyrimidinbasen sowie Xanthin und Hypoxanthin und synthetisierte Theophyllin. Er legte damit die Grundlagen für die Doppelhelixstruktur der DNA.

Kossel war ein hervorragender Lehrer und hat viele deutsche und ausländische Wissenschaftler ausgebildet. Seine Emeritierung 1918 wurde von den enttäuschten Studenten verhindert, er durfte noch bis 1927 die Vorlesung „Physiologische Chemie" halten. Kossel erhielt 1910 den Nobelpreis in Physiologie und Medizin für seine Forschungen in Zellbiologie und die chemische Zusammensetzung des Zellkerns und der Nukleinsäuren.

\section{Literatur}

Jones ME (1953) Albrecht Kossel. A biographical sketch. Yale J Biol Med 26:80-97

Kossel A (1910) Nobel lecture. The chemical composition of the cell nucleus

Kossel A (1921) Leitfaden für Medizinisch-chemische Kurse, 8. Aufl. Fischer's Medizinische Buchhandlung H. Kornfeld, Berlin 